\title{
Helping Us Heal: telephone versus in-person marital communication and support counseling for spouse caregivers of wives with breast cancer
}

\author{
Frances Marcus Lewis ${ }^{1,2} \cdot$ Kristin A. Griffith $^{1} \cdot$ Kuan-Ching Wu${ }^{1} \cdot$ Mary Ellen Shands ${ }^{1} \cdot$ Ellen H. Zahlis $^{1}$
}

Received: 8 February 2021 / Accepted: 13 July 2021 / Published online: 13 August 2021

○ The Author(s), under exclusive licence to Springer-Verlag GmbH Germany, part of Springer Nature 2021

\begin{abstract}
Purpose (1) To test the short-term impact of Helping Us Heal (HUSH), a telephone-delivered counseling program for spouse caregivers of women with breast cancer. (2) To compare outcomes from HUSH with outcomes from a historical control group which received the same program in-person.

Methods Two-group quasi-experimental design using both within- and between-group analyses with 78 study participants, 26 in the within-group and 52 in the between-group analyses. Spouse caregivers were eligible if the wife was diagnosed within 8 months with stage $0-$ III breast cancer and were English-speaking. After obtaining signed informed consent and baseline data, 5 fully scripted telephone intervention sessions were delivered at 2 -week intervals by patient educators. Spouses and diagnosed wives were assessed on standardized measures of adjustment at baseline and immediately after the final intervention session.

Results Within-group analyses revealed that spouses and wives in HUSH significantly improved on depressed mood and anxiety; spouses improved on self-efficacy and their skills in supporting their wife. Additionally, wives' appraisal of spousal support significantly improved. Between-group analyses revealed that outcomes from $H U S H$ were comparable or larger in magnitude to outcomes achieved by the in-person delivered program.

Conclusions A manualized telephone-delivered intervention given directly to spouse caregivers can potentially improve adjustment in both spouses and diagnosed wives but study outcomes must be interpreted with caution. Given the small samples in the pilot studies and the absence of randomization, further testing is needed with a more rigorous experimental design with a larger study sample.
\end{abstract}

Keywords Spouses $\cdot$ Caregivers $\cdot$ Self-efficacy $\cdot$ Breast neoplasms $\cdot$ Telephone $\cdot$ Counseling

\section{Background and significance}

There is growing evidence that spouse caregivers' distress during initial diagnosis and treatment for breast cancer goes well beyond simple caregiving burden [7, 37]. An estimated $22-32 \%$ of spouse caregivers reach or exceed clinical levels of anxiety or depressed mood or both $[14,21]$ and a

Frances Marcus Lewis

fmlewis@u.washington.edu

1 Department of Child, Family \& Population Health, University of Washington, 1959 Pacific Street, Box 357262, Seattle, WA 98195, USA

2 Division of Public Health Sciences Clinical Research Division, Fred Hutchinson Cancer Research Center, Seattle, WA, USA small but growing literature suggests that caregiving puts the spouse at risk for dysregulation of their inflammatory pathways $[4,9,17,25]$. This dysregulation can occur either through activation of the hypothalamic-pituitary-adrenal (HPA) axis or the autonomic nervous system and may occur early during diagnosis and initial treatment. This early dysregulation has the potential to put the spouse caregiver at heightened risk for future health-related threats [25].

Significantly elevated levels of spousal distress (anxiety, depressed mood) have negative consequences for the diagnosed wife, diminishing the spouse's emotional accessibility and increasing the spouse's criticism of the patient, all of which negatively affect the support spouses are able to offer or how couples cope with the cancer $[1,3,10,18,20,31]$. 
Distress in the spouse is not about temporary sadness. In the seminal study by Northouse, spousal distress (BSI: brief symptom inventory) remained higher than a reference population of spouses at 3 days, 30 days, and 18 months post-surgically [21]. The woman's breast cancer impacts the assumptive world of the spouse and shatters it for some [39]. Spouses often feel helpless and emotionally overwhelmedunable to assist themselves or their wives with the diagnosis. They report that their daily life and function are impacted; some suffer from excessive sleep loss or worry about having accidents at work [14]. Spouses struggle with what to say or do to support their wives, often feeling unsuccessful in their attempts [39].

Despite the magnitude of spousal distress, altered marital communication, and diminished interpersonal support, very few interventions have been designed or successful in affecting these outcomes. Prior research by Scott's team is a notable exception [27]. Testing the United We Stand Program with 94 couples facing cancer (57 with breast cancer and 37 with mostly cervical cancer), couples were randomly assigned to 1 of 3 treatment conditions: medical information education (MI), patient coping training (PC), or couple-coping training (CanCOPE). Interventions were delivered by registered psychologists and CanCOPE was offered as conjoint therapy to both members of the couple and involved five, 2-h sessions and two, 30-min telephone calls. Results were mixed. Compared to the other 2 groups, couples in CanCOPE demonstrated significantly lower "coping effort" and women were significantly less psychologically distressed. However, there were no significant effects on spouses' psychological distress. The study's authors also identified multiple methodological limitations that constrained their own enthusiasm: attrition rates between pre- and post-intervention measures were high; the measure of "couple communication," a major outcome variable, did not vary across the 3 measurement periods and therefore could not be used to assess the effects of the intervention.

The intervention to be tested in the current study, the Helping Us Heal Program (HUSH), was designed to reduce spouse caregivers' and patients' distress, not require conjoint delivery, be easily delivered, be offered by telephone, be administered by trained patient educators, consist of fewer and briefer sessions than interventions in prior studies, be fully manualized, and be potentially sustainable.

The current study has two study aims: (1) to test the short-term impact of the HUSH program on spouse caregivers' and wives' behavioral-emotional adjustment to recently diagnosed breast cancer and (2) to compare spouse caregivers' and diagnosed wives' outcomes from the $\mathrm{HUSH}$ telephone-delivered program with the same program delivered in-person.

\section{Methods}

Study participants were recruited from medical providers in the Pacific Northwest. Spouses were eligible if they were married or co-inhabiting with a female intimate partner diagnosed with local or regional breast cancer (stages 0 through 3) within the recent 8 months and read and write English as one of their languages of choice. The study was reviewed and approved by the Human Subjects Committee at the study center and by the institutional review board at each recruitment site. All study participants completed the study prior to the COVID-19 pandemic.

Study sample for within-group design The study sample for the within-group design consisted of 13 spouses and 13 wives (Table 1). Six of the wives $(46.2 \%)$ had stage I breast cancer. An additional $23.1 \%(n=3)$ had stage II and $15.4 \%$ $(n=2)$ had stage III breast cancer. A small percent $(15.4 \%$, $n=2$ ) was diagnosed with (stage 0 ) ductal carcinoma in situ. Most wives $(92.3 \%, n=12)$ were Caucasian; one was of Asian descent. The majority of spouses $(92.3 \% ; n=12)$ were Caucasian; one was Filipino. Wives were diagnosed an average of 3.2 (SD 2.0) months prior, median 2.6 months. Nine (69.2\%) received chemotherapy, radiation therapy, or both at the time of participation in the study. Most wives $(n=12$, $92.3 \%)$ were treated with breast-conserving surgery; 1 (7.7\%) had a mastectomy. Spouses averaged 55.5 (SD 12.4) years of age and wives averaged 53.8 (SD 12.2) years. The majority of wives $(69.2 \%)$ and spouses $(76.9 \%)$ had college degrees or higher, and most wives (50\%) and spouses $(61.5 \%)$ worked full or part time. Spouses were married an average of 23.4 (SD 15.8) years.

Study sample for between-group design The historical control group involved 26 spouses and 26 wives, but no outcome data were obtained on the diagnosed wives. Spouses averaged 54.3 (SD 9.4) years of age and wives averaged 49.2 (SD 9.7) years. The majority of wives $(73.1 \%)$ and spouses $(80.8 \%)$ had college degrees or higher, and over half of the wives $(53.8 \%)$ and spouses $(88.5 \%)$ worked full or part time. Spouses were married an average of 19.0 (SD 11.7) years. All wives were Caucasian and $92.3 \%(n=24)$ of the spouses were Caucasian; one spouse was of Asian descent and one spouse declined to identify his ethnicity. Wives were diagnosed an average of 4.9 (SD 1.5) months prior to enrollment, median 5.4 months. Sixteen $(61.5 \%)$ received chemotherapy, radiation therapy, or both during their participation in the study. Twelve wives $(46.2 \%)$ were treated with breastconserving surgery; 11 (42.3\%) were surgically treated with mastectomies; and three women had not had surgery at the time of entry into the study. 
Table 1 Study sample descriptions: demographic, diagnostic, and treatment data

\begin{tabular}{|c|c|c|c|c|}
\hline \multirow[b]{2}{*}{ Demographics } & \multicolumn{2}{|l|}{ HUSH pilot } & \multicolumn{2}{|l|}{ HHH pilot } \\
\hline & Mean (SD) & Median & Mean (SD) & Median \\
\hline Spouse age & $55.5(12.4)$ & 53 & $54.3(9.4)$ & 53.5 \\
\hline Wife age & $53.8(12.2)$ & 52 & $49.2(9.7)$ & 49 \\
\hline \multirow[t]{2}{*}{ Years in relationship } & $23.4(15.8)$ & 23.8 & $19.0(11.7)$ & 17.5 \\
\hline & $N(\%)$ & & $N(\%)$ & \\
\hline Spouse college graduate or higher & $10(76.9 \%)$ & & $21(80.8 \%)$ & \\
\hline Wife college graduate or higher & $9(69.2 \%)$ & & $19(73.1 \%)$ & \\
\hline Spouse Employed full or part-time & $8(61.5 \%)$ & & $23(88.5 \%)$ & \\
\hline Wife employed full or part-time & $6(50 \%)$ & & $14(53.8 \%)$ & \\
\hline Spouse Caucasian & $12(92.3 \%)$ & & $24(92.3 \%)$ & \\
\hline Wife Caucasian & $12(92.3 \%)$ & & $26(100 \%)$ & \\
\hline \multicolumn{5}{|l|}{ Diagnosis and treatment information } \\
\hline Months since diagnosis & $3.2(2.0)$ & 2.6 & $4.9(1.5)$ & 5.4 \\
\hline \multicolumn{5}{|l|}{ Stage of breast cancer } \\
\hline 0 & $2(15.4 \%)$ & & $2(7.7 \%)$ & \\
\hline I & $6(46.2 \%)$ & & $6(23.1 \%)$ & \\
\hline II & $3(23.1 \%)$ & & $7(26.9 \%)$ & \\
\hline III & $2(15.4 \%)$ & & $5(19.2 \%)$ & \\
\hline Unknown/NA & 0 & & $6(23.1 \%)$ & \\
\hline Receiving treatment at study entry & $9(69.2 \%)$ & & $16(61.5 \%)$ & \\
\hline \multicolumn{5}{|l|}{ Type of surgery } \\
\hline Breast biopsy or breast conserving & $12(92.3 \%)$ & & $12(46.2 \%)$ & \\
\hline Partial or full mastectomy & $1(7.7 \%)$ & & $11(42.3 \%)$ & \\
\hline Surgery not yet performed & & & $3(11.5 \%)$ & \\
\hline
\end{tabular}

Study measures Standardized self-report measures of adjustment were used to assess outcomes. Demographic and background information were obtained through self-report. Disease staging was verified by the site intermediary.

Depressed mood Depressed mood was measured by the Center for Epidemiological Studies-Depression Scale (CESD) $[23,26,28,35,36]$. The CES-D is a 20-item self-report scale measuring the frequency with which symptoms of depressed mood are experienced within the past week [23]. The scale is sensitive to changes in depressed mood over time [34] and the internal consistency reliability (Cronbach's alpha) is 0.85 or higher $[5,24]$. Total scores on the CES-D range from 0 to 60 ; the mean score for a community sample was 9.25 [23]. A score of 16 or greater is a cutoff score for clinically elevated depressed mood [23].

Anxiety Anxiety was measured by the 20-item state anxiety scale of Spielberger's State-Trait Anxiety (STAI-Y) Scale [30]. The state anxiety scale evaluates current feelings of apprehension, tension, nervousness, and worry, with a higher score indicating greater anxiety. Internal consistency reliability (Cronbach's alpha) is 0.90 or above in community and population samples $[6,8,19,30]$. A score of 40 or higher is a cutoff point for clinically elevated anxiety.

Spouse skills Spouse skills were measured by a 27 -item questionnaire, What I Do for Her Checklist, that is completed by the spouse and consists of 2 subscales: support to the wife and spouse's self-care skills. The 6-item wife support subscale measures the spouse's interpersonal and emotional support to his wife about the breast cancer. Example items include, "I try to get my wife to talk about her breast cancer when it is bothering her" and "I ask my wife about specific ways I can be supportive to her about her breast cancer." The 6-item self-care subscale measures the spouse's ways of managing the cancer-related stress in the caregiver's own life, including obtaining support from others. Example items include, "I take regular time out for myself;" and "I use support from others to help me cope with her breast cancer." The alpha reliability coefficient for the Spouse Skills Checklist for the wife support subscale was 0.64 and the self-care subscale was 0.51 [15].

Cancer self-efficacy Cancer self-efficacy was measured by a 19-item self-report measure of the spouse's self-confidence 
in their own self-care and their confidence to support their wife. Structured response options range from "Not at all confident" (1) to "Very confident" (10). Higher scores denote higher self-efficacy. The scale has two dimensions: a self-care subscale and a wife-focused subscale. Example items from the self-care scare include, "I can keep myself calm even when my wife's tense or anxious" and "I know what resources to use to help me personally cope with my wife's breast cancer." Example items from the wife-focused subscale include, "I know what to do to be supportive to my wife about the breast cancer" and "I know how to ask my wife questions that help her talk about the breast cancer." The internal consistency reliability for the 19-item version of the CASE was recently evaluated on a sample of 145 spouse caregivers of women diagnosed with stage 0-3 breast cancer (Lewis, HHH R01 Final Report). The internal consistency reliability for the total scale was 0.95 and 0.81 and 0.95 for the self-care and wife-focused subscales, respectively [15].

Marital quality Three aspects of marital quality were measured: marital adjustment, marital communication, and interpersonal support. Marital adjustment was measured by the Dyadic Adjustment Scale (DAS) [29], a 32-item selfreport scale consisting of 4 theoretical subscales: affectional expression, consensus, cohesion, and satisfaction. Internal consistency reliabilities for each of the DAS subscales have been reported as $0.71,0.85,0.75$, and 0.83 , respectively [13]. In a study of 40 child-rearing women with breast cancer and their male partners, the internal consistency reliability was 0.94 for the male partners. The validity of the instrument has been established with significantly higher scores positively associated with higher levels of psychosocial functioning in households of mothers with chronic illness [38] and mothers with breast cancer [16] and its correlation with the LockeWallace Marital Adjustment Scale [29].

Marital communication was measured by the 23 -item Mutuality and Interpersonal Sensitivity Scale (MIS), a selfreported questionnaire consisting of 2 dimensions: Open Communication and Expressing Sad Feelings. Response options range from "Never true" to "Always true" and higher scores reflect greater expressiveness and disclosure in the couple's communication related to the breast cancer. The internal consistency reliabilities for the total scale of the MIS were 0.91 and 0.95 for spouses and wives, respectively. Reliabilities for the Open Communication subscale were 0.86 and 0.92 for spouses and wives, respectively, and 0.81 and 0.88 for the Expressing Sad Feelings subscale for spouses and wives, respectively (Lewis HHH R01 NCI Final Report).

The criterion validity of the MIS was examined by correlating the total and subscale scores on the MIS with total and subscale scores on the Spanier Dyadic Adjustment Scale (satisfaction, cohesion, consensus, and affectional expression), calculated separately for spouses and diagnosed wives in a comparable sample. The MIS total scale correlated 0.58 ( $p<0.001,2$-tailed) with the total scale score of the DAS for data obtained from spouses and $0.56(p<0.001,2$-tailed $)$ for data obtained from diagnosed wives. The 3 subscales of the MIS were all significantly correlated with the 4 subscales on the DAS for both wives' and spouses' data. Correlation coefficients ranged from 0.20 to 0.55 for wives' data and 0.33 to 0.50 for spouses' data; all $p$-values were $<0.001$ (Lewis HHH R01 NCI Final Report).

Appraised spouse support Two measures were obtained of wives' appraised interpersonal support from their spouse, a cancer-specific measure, What $\mathrm{He}$ Does for $\mathrm{Me}$, and the Personal Resource Questionnaire, a general measure of spouse support.

What He Does for Me is an 18-item cancer-specific measure of support that a diagnosed woman with breast cancer completes about her spouse/partner. The self-report scale measures the wife's perception of specific, observable behaviors of support that she received from her spouse related to her breast cancer. Each item asks the wife whether the statement described her spouse's behavior within the past 2 weeks on a scale of 1 ("Never") to 5 ("All of the time"). Example items read, "My husband listens to me when I tell him sad or negative things about my breast cancer;" "My husband starts up conversations with me when I'm sad or worried about my breast cancer;" "My husband accepts my feelings about my breast cancer, no matter what my feelings;" and "My husband talks with me in ways that draw out my fears or concerns about my breast cancer." The internal consistency reliability of the scale was 0.88 in a recently completed randomized clinical trial of caregivers of women with breast cancer [15].

The Personal Resource Questionnaire (PRQ-S) is a selfreport measure of perceived support from the wife's spouse/ partner [32]. The PRQ contains 25 items rated on a 7-point scale ranging from (1) "strongly disagree" to (7) "strongly agree." (The scale was adapted by Lewis with permission from the author of the measure to focus on the spouse's behavior, not social support from everyone in the patient's network.) Scores range from 25 to 175; higher scores denote higher levels of perceived social support.

The PRQ correlated with the Spanier Dyadic Adjustment Scale (DAS) and a measure of family functioning [22]; coefficients ranged from 0.30 to $0.44, p>001$. The internal consistency reliability for the total scale has been reported as 0.90 or above [33]. Weinert and Brandt [32] reported Cronbach's alpha coefficients ranging from 0.79 to 0.88 for the five subscales. 


\section{Session 1: Anchoring Yourself to Be Strong for Her}

- Session 1 focuses on the spouse's personal experience with his wife's breast cancer and what he is doing to deal with it, including what is helping or not helping him. The session assists the spouse learn and practice personal stress-reducing strategies and better understand how personal stress affects the caregiver's ability to support the diagnosed patient.

- Rationale: To be attentive listeners to the diagnosed wife, spouse caregivers need to be able to self- regulate their own anxiety. Elevated anxiety results in a non-attentive, pre-occupied listener who can be interpreted by the wife as uncaring.

\section{Session 2: Listening and Not Fixing: Letting Go of Superman}

- Session 2 helps add to the spouse's skills to be an attentive, non-judgmental listener for the diagnosed patient and her breast-cancer related concerns. Skilled listening involves 3 distinct components, all of which are taught and practiced in the session. Listening in this special way is interpreted as a new way to protect and support the patient.

- Rationale: To be fully attentive and responsive to the patient's breast cancer-related concerns requires that the spouse be a special kind of listener for her. It also requires that the spouse control the tendency to prematurely reassure her or try to "fix" a problem at a time when the patient needs a listener, not a "fixer."

\section{Session 3: Gaining a Deeper Understanding of Her}

- Session 3 builds on skills from Session 2 but adds more advanced skills in helping the spouse gain competencies to help the patient fully elaborate her concerns or feelings about the breast cancer, particularly when she is reticent or withdrawn. These more advanced listening skills help the spouse discover new things about the patient's feelings and thoughts about the breast cancer and how to better support her in ways she views as supportive.

- Rationale: To draw out a wife who is not forthcoming requires a different set of skills than helping a wife talk about things she is already talking about. In the absence of Session 3, a spouse will try to guess the patient's thoughts or feelings, typically becoming exhausted or discouraged by guessing. Worse yet, the spouse may not "read" the patient's behavior accurately, including what she wants as support from him. These incorrect guesses lead to heightened tension in their relationship.

\section{Session 4: Connecting with Her: Creating Special Times}

- Session 3 introduces 3 new strategies the spouse can use when talking about the breast cancer is not all that is needed. These new strategies, unlike prior sessions, do not rely on verbally communicating and instead rely on ways to behaviorally connect as a couple.

- Rationale: Couple communication requires more than communication skills; it requires ways of physically relating to each other as a couple but does not require coitus when one or both members of the dyad is not ready or able. Non-verbal, physical, and other ways to intimately connect as a couple are also needed.

\section{Session 5: Putting the Pieces Together}

- Session 5 adds to the spouse's skills to identify ways to sustain the skills that were gained from the program. It explicitly engages the spouse in reflecting back on the acquired skills, using the caregiver's own words. It also involves the caregiver identifying skills and competencies the caregiver wants to take forward and sustain in future situations.

- Rationale: Changing skills is distinct from enhancing self-efficacy. Changes in self-efficacy require that the spouse caregiver reflect and evaluate the caregiver's own changed behavior or gains, thereby developing a new sense of self as competent and confident. Specific self-reflection exercises in the session that are designed to add to the spouse's efficacy, not just add to the caregiver's skills.

\section{Used with permission from PsychoOncology[14]}

Fig. 1 Description and rationale for intervention sessions. Used with permission from PsychoOncology [14] 
Table 2 Spouses' outcomes in HUSH and HHH pilot study: pre- and post-intervention scores [within-group analysis]

\begin{tabular}{|c|c|c|c|c|c|c|}
\hline & \multicolumn{3}{|l|}{ HUSH $(n=13)$} & \multicolumn{3}{|c|}{ HHH pilot $(n=26)$} \\
\hline & Mean (SD) & Median & $p^{*}$ & Mean (SD) & Median & $p^{*}$ \\
\hline \multicolumn{7}{|c|}{ Mood and anxiety } \\
\hline \multicolumn{7}{|c|}{ CES-D Depressed Mood } \\
\hline Pre-test & $17.23(9.40)$ & 17.00 & 0.007 & $8.88(8.31)$ & 6.0 & 0.005 \\
\hline Post-test & $10.92(6.92)$ & 10.00 & & $5.31(5.01)$ & 3.5 & \\
\hline \multicolumn{7}{|c|}{ STAI-Y State Anxiety } \\
\hline Pre-test & $40.54(8.54)$ & 40.0 & 0.041 & $33.04(11.4)$ & 31.0 & 0.001 \\
\hline Post-test & $34.69(8.71)$ & 36.0 & & $27.35(9.39)$ & 23.5 & \\
\hline \multicolumn{7}{|l|}{$\underline{\text { Self-efficacy }}$} \\
\hline \multicolumn{7}{|c|}{ CASE Total Scale } \\
\hline Pre-test & $103.38(29.28)$ & 102.00 & 0.001 & $122.98(28.35)$ & 123.0 & $<.001$ \\
\hline Post-test & $155.69(16.29)$ & 157.00 & & $158.83(14.24)$ & 151.0 & \\
\hline \multicolumn{7}{|c|}{ CASE Wife-Focused Subscale } \\
\hline Pre-test & $76.62(24.12)$ & 74.00 & 0.001 & $90.83(20.88)$ & 91.0 & $<.001$ \\
\hline Post-test & $116.54(12.47)$ & 117.00 & & $117.35(11.04)$ & 118.0 & \\
\hline \multicolumn{7}{|c|}{ CASE Self-Care Subscale } \\
\hline Pre-test & $26.77(6.27)$ & 28.00 & 0.002 & $32.04(8.46)$ & 31.0 & $<.001$ \\
\hline Post-test & $39.15(4.22)$ & 39.00 & & $41.48(5.32)$ & 43.0 & \\
\hline \multicolumn{7}{|c|}{ Marital quality } \\
\hline \multicolumn{7}{|l|}{ MIS-Total } \\
\hline Pre-test & $88.00(13.51)$ & 88.00 & 0.753 & $84.16(15.34)$ & 84.0 & 0.797 \\
\hline Post-test & $89.08(10.32)$ & 88.00 & & $83.42(13.37)$ & 84.0 & \\
\hline \multicolumn{7}{|c|}{ MIS-Open Communication Scale } \\
\hline Pre-test & $30.15(4.10)$ & 30.00 & 0.362 & $28.93(6.18)$ & 29.0 & 0.586 \\
\hline Post-test & $31.08(3.80)$ & 31.00 & & $29.15(5.23)$ & 29.5 & \\
\hline \multicolumn{7}{|c|}{ MIS_Expressing Sad Feelings Scale } \\
\hline Pre-test & $33.62(6.98)$ & 32.00 & 0.478 & $31.51(6.42)$ & 32.0 & 0.670 \\
\hline Post-test & $33.77(4.55)$ & 33.00 & & $31.04(5.92)$ & 31.0 & \\
\hline \multicolumn{7}{|c|}{ Spanier Dyadic Adjustment: Total Scale } \\
\hline Pre-test & $111.51(12.30)$ & 112.00 & 0.136 & $112.94(17.10)$ & 115.6 & 0.345 \\
\hline Post-test & $115.29(14.26)$ & 113.00 & & $114.91(14.21)$ & 117.0 & \\
\hline \multicolumn{7}{|c|}{ Spanier Subscale, Consensus } \\
\hline Pre-test & $49.16(6.70)$ & 49.00 & 0.196 & $49.16(8.58)$ & 51.0 & 0.565 \\
\hline Post-test & $51.08(6.71)$ & 49.00 & & $49.72(6.43)$ & 51.0 & \\
\hline \multicolumn{7}{|c|}{ Spanier Subscale, Satisfaction } \\
\hline Pre-test & $38.15(4.96)$ & 38.00 & 0.281 & $38.68(5.93)$ & 41.0 & 0.170 \\
\hline Post-test & $39.14(5.18)$ & 37.00 & & $39.40(5.57)$ & 40.0 & \\
\hline \multicolumn{7}{|c|}{ Spanier Subscale, Affectional } \\
\hline \multicolumn{7}{|l|}{ Expression } \\
\hline Pre-test & $8.27(2.00)$ & 9.00 & 0.085 & $8.22(2.36)$ & 9.0 & 0.032 \\
\hline Post-test & $8.85(2.34)$ & 10.00 & & $8.83(2.17)$ & 10.0 & \\
\hline \multicolumn{7}{|c|}{ Spanier Subscale, Cohesion } \\
\hline Pre-test & $15.92(3.20)$ & 16.00 & 0.465 & $16.88(3.02)$ & 17.0 & 0.951 \\
\hline Post-test & $16.23(2.92)$ & 17.00 & & $16.96(3.38)$ & 16.0 & \\
\hline \multicolumn{7}{|c|}{ What I Do for Her Self-Care Subscale } \\
\hline Pre-test & $17.62(4.19)$ & 18.00 & 0.233 & $17.40(3.66)$ & 18.0 & 0.008 \\
\hline Post-test & $19.23(2.55)$ & 19.00 & & $19.48(3.31)$ & 19.0 & \\
\hline Wife-Suppo & & & & & & \\
\hline Pre-test & $21.07(3.51)$ & 19.00 & 0.008 & $22.52(2.74)$ & 22.0 & 0.016 \\
\hline Post-test & $25.15(2.70)$ & 26.00 & & $24.12(2.95)$ & 25.0 & \\
\hline
\end{tabular}

${ }^{*}$ Wilcoxon signed ranks test; 2-tailed test 
Table 3 Diagnosed wives' outcomes in $H U S H$ [within-group analysis]

\begin{tabular}{|c|c|c|c|}
\hline & \multicolumn{3}{|l|}{ HUSH $(n=13)$} \\
\hline & Mean (SD) & Median & $p^{*}$ \\
\hline \multicolumn{4}{|c|}{ Mood and anxiety } \\
\hline \multicolumn{4}{|c|}{ CES-D Depressed Mood } \\
\hline Pre-test & $14.88(9.53)$ & 15.00 & \multirow[t]{2}{*}{0.05} \\
\hline Post-test & $10.31(6.92)$ & 12.00 & \\
\hline \multicolumn{4}{|c|}{ STAI-Y State Anxiety } \\
\hline Pre-test & $37.00(6.03)$ & 35.00 & \multirow[t]{2}{*}{0.00} \\
\hline Post-test & $27.77(5.31)$ & 28.00 & \\
\hline \multicolumn{4}{|c|}{ Marital quality } \\
\hline \multicolumn{4}{|c|}{ MIS-Total } \\
\hline Pre-test & $89.06(14.73)$ & 90.00 & \multirow[t]{2}{*}{0.89} \\
\hline Post-test & $88.36(13.16)$ & 95.00 & \\
\hline \multicolumn{4}{|c|}{ MIS-Open Communication } \\
\hline Pre-test & $35.08(6.24)$ & 37.00 & \multirow[t]{2}{*}{0.78} \\
\hline Post-test & $35.23(5.48)$ & 36.00 & \\
\hline \multicolumn{4}{|c|}{ MIS_-Talking About Sad Thoughts } \\
\hline Pre-test & $36.14(6.44)$ & 39.00 & \multirow[t]{2}{*}{0.84} \\
\hline Post-test & $35.97(5.77)$ & 38.00 & \\
\hline \multicolumn{4}{|c|}{ Spanier Dyadic Adjustment: Total } \\
\hline Pre-test & $114.31(18.63)$ & 121.00 & \multirow[t]{2}{*}{0.68} \\
\hline Post-test & $113.37(17.40)$ & 119.00 & \\
\hline \multicolumn{4}{|c|}{ Spanier Subscale, Consensus } \\
\hline Pre-test & $50.23(8.96)$ & 50.00 & \multirow[t]{2}{*}{0.72} \\
\hline Post-test & $49.69(8.79)$ & 47.00 & \\
\hline \multicolumn{4}{|c|}{ Spanier Subscale, Satisfaction } \\
\hline Pre-test & $39.69(5.07)$ & 41.00 & \multirow[t]{2}{*}{0.81} \\
\hline Post-test & $39.44(5.22)$ & 39.00 & \\
\hline \multicolumn{4}{|c|}{ Spanier Subscale, Affectional Expression } \\
\hline Pre-test & $8.77(2.17)$ & 9.00 & \multirow[t]{2}{*}{0.96} \\
\hline Post-test & $8.77(2.24)$ & 9.00 & \\
\hline \multicolumn{4}{|c|}{ Spanier Subscale, Cohesion } \\
\hline Pre-test & $15.62(4.33)$ & 17.00 & \multirow[t]{2}{*}{0.42} \\
\hline Post-test & $15.46(3.10)$ & 14.00 & \\
\hline \multicolumn{4}{|c|}{ What He Does for Me } \\
\hline Pre-test & $68.23(11.39)$ & 71.00 & \multirow[t]{2}{*}{0.07} \\
\hline Post-test & $71.91(8.53)$ & 76.00 & \\
\hline \multicolumn{4}{|c|}{ Personal Resource Questionnaire } \\
\hline Pre-test & $139.31(20.16)$ & 139.00 & \multirow[t]{2}{*}{0.03} \\
\hline Post-test & 146.38 (15.38) & 148.00 & \\
\hline
\end{tabular}

*Wilcoxon signed ranks test; 2-tailed test

\section{Description of the Helping Us Heal Program}

The theoretical framework for the HUSH program is based on an integration of the Relational Model of Adjustment to Cancer and Bandura's Social-Cognitive Theory [2, 11, 12, 12] (see Fig. 1 for a brief description of each session and its rationale [14]). Telephone-delivered sessions were scheduled at 2-week intervals.

Dosage and fidelity were monitored and protected in four ways: through initial training of the nurse patient educators; discussing the intervention sessions during weekly meetings; and using a fully scripted intervention manual and spouse workbook to guide each intervention session.

The intervention manual and spouse's workbook for the $H U S H$ program were the same intervention materials used for the in-person Helping Her Heal program. However, the HUSH program was delivered by telephone (cell or land line), and the spouse's workbook was mailed in advance of delivering the intervention sessions.

\section{Study results for study aim 1}

Outcomes from the within-group design are summarized in Tables 2 and 3.

Depressed mood and anxiety Spouses were significantly less depressed $(p=0.01)$ and less anxious $(p=0.04)$ after the intervention compared to baseline. Wives were also significantly less depressed $(p=0.05)$ and less anxious $(p=0.001)$ post-intervention compared to baseline.

Spouse support Spouse interpersonal support significantly improved. Spouses scored significantly higher on their self-reported support to their wife compared to baseline $(p=0.008)$ on the standardized measure, What I Do for Her. Additionally, wives' appraisal of spousal support improved on two measures. It significantly increased on the Personal Resource Questionnaire compared to baseline $(p=0.03)$ and it tended to significantly increase on Appraised Spouse Support to $\mathrm{Me}(p=0.07)$.

Self-efficacy Spouses scored significantly higher on the CASE total scale and the two subscales compared to baseline. More specifically, spouses significantly improved on total self-efficacy $(p=0.001)$, in their confidence to manage the impact of the cancer on their wife $(p=0.001)$, and in their confidence to carry out their own self-care compared to baseline ( $p=0.002)$.

Marital quality Contrary to expectation, spouses' and wives' scores on marital adjustment (Spanier Dyadic Adjustment) and marital communication (MIS) did not significantly change. There were no improvements in either the total or subscales of these measures.

In addition to examining pre- and post-intervention scores on the standardized measures, the proportion of spouses and wives scoring in the clinical range of distress at baseline 
Table 4 Changes in spouses' and wives' clinical cutoff scores on CES-D, STAI, and DAS in HUSH and HHH pilot

\begin{tabular}{|c|c|c|c|c|}
\hline & \multicolumn{2}{|l|}{ HUSH pilot } & \multicolumn{2}{|l|}{ HHH pilot } \\
\hline & Above cutoff at baseline & Above cutoff at post-test & Above cutoff at baseline & $\begin{array}{l}\text { Above } \\
\text { cutoff at } \\
\text { post-test }\end{array}$ \\
\hline Spouses' scores & $n=13$ & & $n=26$ & \\
\hline \multicolumn{5}{|c|}{ CES-D Depressed Mood $\geq 16$} \\
\hline Yes & 8 & 3 & 6 & 1 \\
\hline No & 5 & 0 & 20 & 1 \\
\hline \multicolumn{5}{|l|}{ STAI-Y State Anxiety $>39$} \\
\hline Yes & 7 & 3 & 7 & 3 \\
\hline No & 6 & 0 & 19 & 0 \\
\hline \multicolumn{5}{|l|}{ Spanier-Total Scale $<100$} \\
\hline Yes & 3 & 2 & 4 & 3 \\
\hline No & 10 & 1 & 21 & 1 \\
\hline Diagnosed wives' scores & $\begin{array}{l}\text { HUSH pilot } \\
n=13\end{array}$ & & & \\
\hline \multicolumn{5}{|c|}{ CES-D Depressed Mood $\geq 16$} \\
\hline Yes & 6 & 1 & & \\
\hline No & 7 & 2 & & \\
\hline \multicolumn{5}{|l|}{ STAI-Y State Anxiety $>39$} \\
\hline Yes & 4 & 0 & & \\
\hline No & 9 & 0 & & \\
\hline \multicolumn{5}{|c|}{ Spanier-Total Scale $<100$} \\
\hline Yes & 2 & 2 & & \\
\hline No & 11 & 2 & & \\
\hline
\end{tabular}

were calculated and compared with their scores post-intervention (see Table 4). In all cases, the proportion of wives and spouses who scored in the clinical range of distress at post-intervention decreased compared to baseline and there was no evidence of backsliding.

\section{Study results for study aim 2}

Results from the between-groups analyses are summarized in Table 5, comparing HUSH outcomes with outcomes from the in-person historical comparison group [14].

To compare HUSH outcomes with outcomes from the comparison group, difference scores were first computed between baseline and post-intervention scores for each group. These difference scores $(d)$ were calculated on each standardized measure. The calculated difference or $d$ score was then compared between groups using the Mann-Whitney $U$ statistic for independent samples.

Results revealed that difference $(d)$ scores on virtually all the HUSH outcome measures were comparable in magnitude to scores obtained from participants in the in-person delivered program. That is, there were no statistically significant differences in $d$ scores on any of the outcome variables between the telephone-delivered and in-person delivered program. This means there were no differential benefits for spouses receiving the in-person program compared to those receiving the telephone-delivered program. Additionally, the HUSH appears to work more effectively than the $\mathrm{HHH}$ in improving spouse caregivers' self-efficacy. Increases in the total scale score of the CASE in HUSH improved $50.6 \%$; the wife-focused and self-focused subscales improved $52.1 \%$ and $46.3 \%$, respectfully. In contrast, the in-person program showed an improvement of $29.3 \%$ for the total score of the CASE and $29.2 \%$ and $29.4 \%$ for the wife- and self-carefocused subscales, respectively.

\section{Discussion of results}

Results from these two small sample pilot studies suggest that the Helping Us Heal (HUSH) program may be of potential benefit to spouse caregivers and their diagnosed wives. Both wives and spouses became significantly less anxious and depressed. Spouses significantly improved in their skills (What I Do for Her), in their self-confidence to 
Table 5 Comparison of difference scores on spouse outcomes between HHH pilot study $(n=26)$ and $H U S H(n=13)$ [betweengroup analysis]

\begin{tabular}{|c|c|c|c|c|}
\hline & Mean (SD) & Median & $p^{*}$ & Percent change \\
\hline \multicolumn{5}{|c|}{ Mood and anxiety } \\
\hline \multicolumn{5}{|c|}{ CES-D Depressed Mood } \\
\hline HHH pilot & $3.58(6.10)$ & 3.0 & 0.12 & \\
\hline HUSH & $6.31(6.07)$ & 7.0 & & \\
\hline \multicolumn{5}{|c|}{ STAI-Y State Anxiety } \\
\hline HHH pilot & $5.69(7.68)$ & 3.0 & 0.83 & \\
\hline HUSH & $5.85(8.42)$ & 6.0 & & \\
\hline \multicolumn{5}{|l|}{ Self-efficacy } \\
\hline \multicolumn{5}{|c|}{ CASE Total Scale } \\
\hline HHH pilot & $35.96(26.72)$ & 33.0 & & 29.3 \\
\hline HUSH & $52.31(32.22)$ & 48.0 & 0.23 & 50.6 \\
\hline \multicolumn{5}{|c|}{ CASE Wife-Focused Subscale } \\
\hline HHH pilot & $26.52(21.54)$ & 35.0 & 0.19 & 29.2 \\
\hline HUSH & $39.92(25.59)$ & 35.0 & & 52.1 \\
\hline \multicolumn{5}{|c|}{ CASE Self-Care Subscale } \\
\hline HHH pilot & $9.43(8.54)$ & 11.0 & 0.44 & 29.4 \\
\hline HUSH & $12.38(7.81)$ & 11.0 & & 46.3 \\
\hline \multicolumn{5}{|l|}{ Marital quality } \\
\hline \multicolumn{5}{|l|}{ MIS-Total } \\
\hline HHH pilot & $-0.74(12.12)$ & 0.0 & 0.55 & \\
\hline HUSH & $1.08(13.29)$ & 5.0 & & \\
\hline \multicolumn{5}{|c|}{ MIS_-Open Communication Scale } \\
\hline HHH pilot & $0.23(4.72)$ & 0.5 & & \\
\hline HUSH & $0.92(4.29)$ & 2.0 & 0.665 & \\
\hline \multicolumn{5}{|c|}{ MIS_Expressing Sad Feelings Scale } \\
\hline HHH pilot & $-0.47(5.63)$ & 0.0 & & \\
\hline HUSH & $0.15(6.09)$ & 2.0 & 0.40 & \\
\hline \multicolumn{5}{|c|}{ Spanier Dyadic Adjustment: Total Scale } \\
\hline HHH pilot & $1.97(7.61)$ & 0.0 & & \\
\hline HUSH & $3.78(7.94)$ & 3.0 & 0.51 & \\
\hline \multicolumn{5}{|c|}{ Spanier Subscales, Consensus } \\
\hline HHH pilot & $0.56(4.74)$ & 0.0 & 0.40 & \\
\hline HUSH & $1.92(5.02)$ & 2.0 & & \\
\hline \multicolumn{5}{|c|}{ Spanier Subscales, Satisfaction } \\
\hline HHH pilot & $0.72(2.59)$ & 0.0 & 0.78 & \\
\hline HUSH & $0.98(2.74)$ & 0.77 & & \\
\hline \multicolumn{5}{|c|}{ Spanier Subscales, Affectional Expression } \\
\hline HHH pilot & $0.61(1.33)$ & 0.0 & 0.92 & \\
\hline HUSH & $0.58(1.15)$ & 0.0 & & \\
\hline \multicolumn{5}{|c|}{ Spanier Subscales, Cohesion } \\
\hline HHH pilot & $0.08(1.68)$ & 0.0 & 0.54 & \\
\hline HUSH & $0.31(1.60)$ & 1.0 & & \\
\hline \multicolumn{5}{|l|}{ Spouse skills } \\
\hline \multicolumn{5}{|c|}{ Self-care Subscale } \\
\hline HHH pilot & $2.08(3.46)$ & 2.0 & 0.84 & \\
\hline HUSH & $1.62(4.54)$ & 2.0 & & \\
\hline \multicolumn{5}{|c|}{ Wife-support Subscale } \\
\hline HHH pilot & $1.60(3.38)$ & 1.0 & 0.12 & \\
\hline HUSH & $4.08(4.00)$ & 5.0 & & \\
\hline
\end{tabular}

*Mann-Whitney $U$ test, 2-tailed: between-group analysis comparing difference score $(d)$ between $H U S H$ and $\mathrm{HHH}$ pilot study better manage the pressures of the cancer on themselves (CASE-self-care subscale), and in their self-confidence in communicating with and supporting their wife about her breast cancer (CASE wife-focused subscale). Wives also increased significantly in their positive appraisal of their spouses' support (Personal Resource Questionnaire). Given the pre-experimental design of the study design, caution is in order. Results for the within-group analysis cannot be unconditionally attributed to the intervention; over time, for example, spouses could have gained competencies and become better adjusted from other sources or on their own, not because of Helping Her Heal.

When outcomes from the HUSH were compared to outcomes from the in-person historical comparison group, the magnitude of changes in outcomes were comparable, suggesting that caregivers' and patients' adjustment might benefit equally from a telephone intervention as an in-person delivered program. Furthermore, improvements in caregivers' self-efficacy in $H U S H$ were greater than improvements from the in-person program. To verify the validity of this result, we tested baseline variances on the CASE for the inperson and the by-telephone intervention for the total scale score and for the two subscales. There were no significant differences between variances at baseline between the two study samples on the total or subscale scores of the CASE.

Contrary to expectation, the telephone-delivered program did not significantly change scores on measures of marital quality. Rather the impact of the HUSH was limited to variables that were directly targeted by the intervention: spouses' and wives' anxiety and depressed mood, spouses' confidence in their own self-care and ability to manage the impact of the cancer on their wife, and spouse- and wife-reported interpersonal support and communication.

Results from the HUSH compare favorably to Scott's results [27]. Although Scott's study evaluated the impact of a relationship-enhancing program on couple communication and spouses' adjustment, only wives benefited from that intervention, not spouses. In HUSH, both wives and spouse caregivers benefited. Furthermore, Scott's intervention required conjoint delivery suggesting it is less scalable and sustainable than the telephone-delivered $\mathrm{HUSH}$.

Results raise an important methodological and theoretical question: Are couples able to improve communication and interpersonal support if only the spouse receives the intervention. The answer appears to be yes. Wives and spouse-caregivers both improved on post-intervention measures even though the spouse was the only member of the dyad who received the intervention. Conjoint sessions were not needed.

Results should be viewed with caution; changes occurred with primarily well-educated Caucasian couples within long-term marriages. The small sample sizes and the absence of randomization precludes unconditionally 
attributing improvements to $H U S H$. Recall that singlegroup designs do not control for multiple threats to the internal validity of study results.

Despite study limitations, current study outcomes suggest that a fully scripted telephone-delivered educational counseling program for spouse caregivers has the potential to positively affect caregivers' communication and support skills, self-management competencies and confidence, and minimize distress in both spouse caregivers and diagnosed wives. Independent of spouses' report of their support and communication with their wives, wives attributed significant improvements in the support they received from their spouses. Taken together, results suggest, but cannot unconditionally claim, that the HUSH changed spouses' behavior and wives experienced that difference. A future study is warranted using a more rigorous experimental design with a larger and more diverse study sample.

Author contribution All authors agreed with the content and gave explicit consent to submit and obtained consent from the responsible authorities at the institute/organization where the work has been carried out, before the work was submitted.

All authors whose names appear on the submission (1) made substantial contributions to the conception or design of the work; or the acquisition, analysis, or interpretation of data; or the creation of new software used in the work; (2) drafted the work or revised it critically for important intellectual content; (3) approved the version to be published; and (4) agree to be accountable for all aspects of the work in ensuring that questions related to the accuracy or integrity of any part of the work are appropriately investigated and resolved.

Funding Research reported in this study was supported by grants from the UW Tennis Fund, University of Washington School of Medicine; University of Washington Medical Center Endowed Professor of Nursing Leadership; Nesholm Family Foundation; Elizabeth Soule Professorship Fund; Oncology Nursing Foundation; and the Research Intramural Fund, University of Washington, School of Nursing.

Availability of data and material The data that support the findings of this study are available on request from the corresponding author.

\section{Code availability N/A.}

\section{Declarations}

Ethical approval Approval was obtained from the ethics committee of University of Washington, Institutional Review Board (HUSH file \# 06-3782-J01 \& Helping Her Heal file \# 02-2002-C0I). The procedures used in this study adhere to the tenets of the Declaration of Helsinki.

Consent to participate Written informed consent was obtained from all participants included in the study.

Conflict of interest The authors declare no competing interests.

\section{References}

1. Baider L, Andritsch E, Goldzweig G, Uziely B, Ever-Hadani P, Hofman G, Krenn G, Samonigg H (2004) Changes in psychological distress of women with breast cancer in long-term remission and their husbands. Psychosomatics 45:58-68

2. Bandura A (1977) Social learning theory. Prentice-Hall, Englewood Cliffs

3. Ben-Zur H, Gilbar O, Lev S (2001) Coping with breast cancer: patient, spouse, and dyad models. Psychosom Med 63:32-39

4. Carlson LE, Bultz BD, Speca M, St. Pierre M (2000) Partners of cancer patients: I. Impact, adjustment, and coping across the illness trajectory. J Psychosoc Oncol 18:39-63

5. Conerly RC, Baker F, Dye J, Douglas CY, Zabora J (2002) Measuring depression in African American cancer survivors: the reliability and validity of the Center for Epidemiologic StudyDepression (CES-D) Scale. J Health Psychol 7:107-114

6. Edwards B, Clarke V (2004) The psychological impact of a cancer diagnosis on families: the influence of family functioning and patients' illness characteristics on depression and anxiety. Psychooncology 13:562-576

7. Feldman B, Broussard CA (2005) The Influence of relational factors on men's adjustment to their partners' newly-diagnosed breast cancer. J Psychosoc Oncol 23:23-43

8. Garvin BJ, Moser DK, Riegel B, McKinley S, Doering LV, An K (2003) Effects of gender and preference for information and control on anxiety early after myocardial infarction. Nurs Res 52:386-392

9. Hansel A, Hong S, Camara RJ, von Kanel R (2010) Inflammation as a psychophysiological biomarker in chronic psychosocial stress. Neurosci Biobehav Rev 35:115-121

10. Heckel L, Fennell K, Reynolds J, Boltong A, Botti M, Osborne R, Mihalopoulos C, Chirgwin J, Williams M, Gaskin C, Ashley D, Livingston P (2018) Efficacy of a telephone outcall program to reduce caregiver burden among caregivers of cancer patients [PROTECT]: a randomised controlled trial. BMC Cancer 18:59

11. Lewis FM (2004) Family-focused oncology nursing research. Oncol Nurs Forum 31:288-292

12. Lewis FM (2009) Advancing family-focused oncology nursing research. In: Phillips JM, King CR (eds) Advancing oncology nursing science. Oncology Nursing Society, Pittsburgh

13. Lewis FM, Casey SM, Brandt PA, Shands ME, Zahlis EH (2006) The enhancing connections program: pilot study of a cognitivebehavioral intervention for mothers and children affected by breast cancer. Psychooncology 15:486-497

14. Lewis FM, Cochrane BB, Fletcher KA, Zahlis EH, Shands ME, Gralow JR, Wu SM, Schmitz K (2008) Helping Her Heal: a pilot study of an educational counseling intervention for spouses of women with breast cancer. Psychooncology 17:131-137

15. Lewis FM, Griffith KA, Alzawad Z, Dawson PL, Zahlis EH, Shands ME (2019) Helping Her Heal: randomized clinical trial to enhance dyadic outcomes in couples. Psychooncology 28:430-438

16. Lewis FM, Zahlis EH, Shands ME, Sinsheimer JA, Hammond MA (1996) The functioning of single women with breast cancer and their school-aged children. Cancer Pract 4:15-24

17. Lutgendorf SK, Laudenslager ML (2009) Care of the caregiver: stress and dysregulation of inflammatory control in cancer caregivers. J Clin Oncol 27:2894-2895

18. Manne S, Glassman M (2000) Perceived control, coping efficacy, and avoidance coping as mediators between spouses' unsupportive behaviors and cancer patients' psychological distress. Health Psychol 19:155-164

19. Moser DK, Dracup K, McKinley S, Yamasaki K, Kim C-J, Bea $R$ (2003) An international perspective on gender differences in 
anxiety early after acute myocardial infraction. Psychomatic Med 65:511-516

20. Northouse LL, MC K, AM S, 23107181. WD-P (2012) The impact of caregiving on the psychological well-being of family caregivers and cancer patients. Semin Oncol Nurs 28:236-245

21. Northouse LL, Swain MA (1987) Adjustment of patients and husbands to the initial impact of breast cancer. Nurs Res 36:221-225

22. Pless IB, Satterwhite B (1973) A measure of family functioning and its application. Soc Sci Med 7:613-620

23. Radloff LS (1977) The CES-D Scale: a self-report depression scale for research in the general population. Appl Psychol Meas $1: 385-401$

24 Rees G, Gledhill J, Garralda ME, Nadel S (2004) Psychiatric outcome following paediatric intensive care unit (PICU) admission: a cohort study. Intensive Care Med 30:1607-1614

25. Rohleder N, Marin TJ, Ma R, Miller GE (2009) Biologic cost of caring for a cancer patient: dysregulation of pro- and anti-inflammatory signaling pathways. J Clin Oncol 27:2909-2915

26. Ross CE, Mirowsky J (1984) Components of depressed mood in married men and women. Am J Epidemiol 119:997-1004

27. Scott JL, Halford WK, Ward BG (2004) United we stand? The effects of a couple-coping intervention on adjustment to early stage breast or gynecological cancer. J Consult Clin Psychol 72:1122-1135

28. Sievers EL, Appelbaum FR, Spielberger RT, Forman SJ, Flowers D, Smith FO, Shannon-Dorcy K, Berger MS, Bernstein ID (1999) Selective ablation of acute myeloid leukemia using antibody-targeted chemotherapy: a phase I study of an anti-CD33 calicheamicin immunoconjugate. Blood 93:3678-3684

29. Spanier GB (1976) Measuring dyadic adjustment: new scales for assessing the quality of marriage and similar dyads. J Marriage Fam 38:15-28

30. Spielberger CD (1983) Manual for the State-Trait Anxiety Inventory (Form Y). Consulting Psychologists Press, Palo Alto
31 Wagner CD, Das LT, Bigatti SM, Storniolo AM (2011) Characterizing burden, caregiving benefits, and psychological distress of husbands of breast cancer patients during treatment and beyond. Cancer Nurs 34:E21-E30

32. Weinert C, Brandt PA (1987) Measuring social support with the Personal Resource Questionnaire. West J Nurs Res 9:589-602

33. Weinert C, Long KA (1993) Support systems for the spouses of chronically ill persons in rural areas. Fam Commun Health 16:46-54

34 Weissman M, Sholomskas D, Pottenger M, Prusoff B, Locke B (1977) Assessing depressive symptoms in five psychiatri populations: a validation study. Am J Epidemiol 106:203-214

35. Weissman MM, Myers JK (1980) Psychiatric disorders in a U.S. community. The application of research diagnostic criteria to a resurveyed community sample. Acta Psychiatr Scand 62:99-111

36. Weissman MM, Myers JK, Thompson WD (1981) Depression and its treatment in a US urban community-1975-1976. Arch Gen Psychiatry 38:417-421

37. Wimberly SR, Carver CS, Laurenceau JP, Harris SD, Antoni MH (2005) Perceived partner reactions to diagnosis and treatment of breast cancer: impact on psychosocial and psychosexual adjustment. J Consult Clin Psychol 73:300-311

38. Zahlis EH, Lewis FM (1998) Mothers' stories of the school-age child's experience with the mother's breast cancer. J Psychosoc Oncol 16:25-43

39. Zahlis EH, Lewis FM (2010) Coming to grips with breast cancer: the spouse's experience with his wife's first six months. J Psychosoc Oncol 28:79-97

Publisher's note Springer Nature remains neutral with regard to jurisdictional claims in published maps and institutional affiliations. 